\title{
Cocinar y alimentarse en tiempos de conquista. Reconstruyendo paquetes culinarios a partir de análisis cerámicos y arqueofaunísticos (Mendoza, siglos XV-XVII)
}

\author{
Leonardo Castillo", Emiliano Araujo "** Horacio Chiavazza** \\ y Cristina Prieto-Olavarría"
}

Recibido:

16 de marzo de 2017

Aceptado:

31 de agosto de 2017

\section{Resumen}

En este trabajo estudiamos los modos de comer y preparar los alimentos en el "valle de Güentata", actual ciudad de Mendoza, entre los siglos XV y XVII. El objetivo es reconstruir parte del paquete culinario a partir de la integración de dos líneas de evidencia y analizando aquellos materiales recuperados en excavaciones arqueológicas en el Área Fundacional de Mendoza: la alfarería indígena y los restos arqueofaunísticos. Desde el marco de la arqueología de la alimentación, analizamos la inclusión de estos materiales en las sucesivas etapas de obtención y distribución del alimento, de la preparación y cocción, y su presencia en el servicio y consumo, en contextos de cambio cultural signados por la conquista española del territorio. Para ello tuvimos en cuenta tres elementos centrales: el medio, las prácticas culturales (técnicas y conformación de dietas) y la ideología. Los resultados permitieron establecer que el sector Pilastra Noroeste del predio Ruinas de San Francisco constituyó originalmente un contexto vinculado a la cocina, donde se habrían combinado técnicas de cocción de tradición indígena con ingredientes tanto locales como exóticos.

Cooking and eating in times of conquest. Rebuilding culinary packages from ceramic and archaeofaunal analysis (Mendoza, XVXVII centuries)

\section{Abstract}

In this article, we study the manner of consuming and preparing food at "Güentata Valley", the present-day city of Mendoza, between the $15^{\text {th }}$ and the $17^{\text {th }}$ centuries. The aim is to reconstruct part of the culinary package by integrating two separate lines of evidence -indigenous pottery and archaeofaunal remains- to study the materials from

\section{Palabras clave}

Arqueología de la alimentación Prácticas culinarias

Zooarqueología

Cerámica

* Instituto Argentino Nivología, Glaciología y Ciencias Ambientales (IANIGLA), Universidad Nacional de Cuyo (UNCu) - CONICET. Av. Ruiz Leal s/n, Parque General San Martín (CP 5500) Mendoza, Argentina. E-mail: Icastillo@mendoza-conicet.gob.ar, cprieto@mendoza-conicet.gob.ar

** Laboratorio de Arqueología Histórica y Etnohistoria (LAH), Instituto de Arqueología y Etnología (IAyE), Facultad de Filosofía y Letras, Universidad Nacional de Cuyo - Centro Investigaciones Ruinas de San Francisco (CIRSF), Área Fundacional, Secretaría de Cultura de la Municipalidad de Mendoza. Centro Universitario, Parque General San Martín (CP M5502JMA), Mendoza, Argentina. E-mail: emilianojavara@gmail.com; hchiavazza@gmail.com 
1. Sanders y Price (1968, p. 194) utilizaron el término Área Clave para referirse a zonas de concentrado poder económico y demográfico, con formas desarrolladas de urbanismo y sostenidas por los sistemas más eficientes de explotación del suelo, de comunicación y de transporte. En el Centro Oeste Argentino, los Valles de Güentata y de Caria se erigieron, al menos luego del arribo del incario, en un "Área

Clave”, concepto que resulta útil para identificarlas como focos de cambio cultural con repercusiones extralocales y a partir de las cuales se estructuraron también las periferias (Bárcena, 1988, 2005; Cahiza, 2001; Dillehay, Williams y Calógero Santoro, 2006; García 1999; Ots, 2007; Parisii, 1994).

2. Prieto y Willoud (1986, p. 4) definen al valle de Güentata como el espacio circunscripto que consideraron como tal los españoles cuando llegaron al territorio cuyano, es decir la zona irrigada por las aguas del río de la ciudad y sus acequias derivadoras. Este espacio al oeste estaba demarcado por las primeras estribaciones precordilleranas, hacia el este por el arroyo

Tulumaya, al norte por una línea imaginaria trazada entre la Punta de Las Lajas-El Plumerillo y al sur la línea que une el Cerro Puntudo y el distrito de la Puntilla. the archaeological excavations undertaken in the Founding City Area of Mendoza. Within the framework of food archeology, we analyze the presence of these materials in the successive stages of obtaining and distributing food, preparation and cooking, their presence in serving and consumption, and in contexts of cultural change marked by Spanish conquest of the region. In addressing this, we took into account three central elements: the environment, cultural practices (techniques and diet composition) and ideology. The results allowed to establish that the Pilastra Noroeste Sector of the Ruinas de San Francisco area was originally a context linked to the kitchen, where indigenous tradition cooking techniques were combined with both local and exotic ingredients.

\section{Introducción}

En este trabajo, que se enmarca en el proceso histórico de conquista y colonización europea iniciado a mediados del siglo XVI en la región de Cuyo, contempla que las prácticas de control desplegadas por los grupos dominantes no fueron unilineales y que dentro de las mismas predominaron interacciones que pusieron en juego relaciones inéditas en y entre los conquistadores españoles y las poblaciones indígenas. El registro de tales interacciones supuso relaciones de poder asimétricas, por lo que el trayecto de transformación social y cultural resultante, generó un proceso de etnogénesis singular (Barth, 1976; Bartolomé, 2006; Chiavazza, 2012; Prieto Olavarría y Chiavazza, 2015). No se trata de un proceso de carácter uniforme, dado que, a nivel planetario, los últimos cinco mil años de historia humana han sido testigos de una incesante serie de encuentros coloniales que han tenido una influencia global significativa en la reestructuración continua de la cultura, la sociedad y la identidad (Dietler, 2010).

Las prácticas culinarias que consideramos aquí se dieron en un período de especial complejidad histórica en la región, donde los grupos originarios huarpes que habitaban

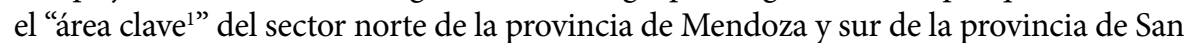
Juan (e.g. Canals Frau, 1946; Michieli, 1983; Prieto, 2000; Rusconi, 1942, 1962) debieron ajustarse a las condiciones propias de un doble proceso de conquista experimentado en poco menos de una centuria. Por un lado, el avance del incario en el siglo XV, que dio forma definitiva a la frontera meridional oriental del Tawantinsuyu (e.g. Bárcena, 1988; Cahiza y Ots, 2005; García, 1999), y por otro, las aproximaciones españolas a la región, acaecidas en el marco de la fundación de la ciudad de Santiago de Chile desde el año 1541. Este avance conquistador implicó una temprana exploración del valle de Güentata ${ }^{2}$, documentado al menos desde 1551, marcando el inicio de un proceso de desestructuración forzada sobre las sociedades locales mediante la institución de la encomienda (Prieto, 2000). Al mismo tiempo, significó el comienzo de una colonización biológica, ocurrida por el arribo de fauna y vegetales exóticos, con sus consecuentes modalidades productivas, configurando incluso una nueva ecología propia de la conquista europea (Arnold, 2000; Chiavazza, 2010; Crosby, 1988). Este proceso cristalizó en su forma jurídica con la fundación de la ciudad de Mendoza en el año 1561.

El arribo de nuevos recursos vegetales y animales no sólo generó un impacto biológico y ambiental sobre el territorio y un nuevo modo de extracción de recursos caracterizado por la rapacidad (Arnold, 2000), sino que además provocó una serie de cambios en los esquemas culturales de las poblaciones locales (Chiavazza, 2012; Mafferra, Chiavazza y Roig, 2015; Prieto y Wuilloud, 1986). Indagar en el modo, el ritmo y la extensión de estos cambios proporciona valiosa información para explicar el proceso de conquista cultural de los territorios cuyanos. La arqueología contribuye a esta explicación en la medida que se vincula con la historia de la expansión del "sistema mundo" capitalista que, desde el siglo XVI en adelante, ha sido responsable de la mayor puesta en marcha 
del colonialismo en la historia mundial (Braudel, 1992; Dietler, 2010; Wallerstein, 1974; Wolf, 2015). En este sentido, la llegada de plantas y animales foráneos que estaban insertos en el marco de un sistema global de producción alimentaria habría originado consecuencias a corto y a largo plazo, ya que los alimentos supusieron nuevas tensiones al transformarse, a la vez, en potencial fuente de nutrición para la mayoría y también de riqueza y poder para una minoría (Harris, 2011).

Las líneas de evidencia arqueológica, tanto cerámica como arqueofaunística, han sido tratadas con diferentes objetivos y profundidad analítica en las investigaciones del sector urbano del norte de Mendoza (e.g. Araujo, 2016; Bárcena y Schávelzon, 1992; Castillo, 2013; Chiavazza, 2001, 2013; Chiavazza y Prieto Olavarría, 2004; Chiavazza y Tamiozzo, 2002; Chiavazza y Zorrilla, 2006; García Llorca, 2003, 2009; Prieto Olavarría y Chiavazza, 2015; Prieto Olavarría y Páez, 2015; Prieto Olavarría y Tobar, 2017; Silveira, 1998; Tobar, 2013). Sin embargo, el estudio de la alimentación como fenómeno cultural no ha sido objeto de mayor atención, siendo una temática poco explorada en la arqueología regional, priorizando su consideración en sentido nutricional y adaptativo de modo excluyente. En este trabajo aportamos, desde la perspectiva de la arqueología de la alimentación, al conocimiento de los modos de preparar los alimentos y comer, a partir de la reconstrucción del paquete culinario de un contexto excavado en el núcleo de la ciudad de Mendoza colonial, el sector Pilastra NO (en adelante PNO) del punto arqueológico Ruinas de San Francisco (en adelante RSF) (Chiavazza, 2010). Para lograr este objetivo se analizaron las sucesivas etapas de obtención y distribución de los alimentos, su preparación, cocción, servicio y consumo, a partir del estudio de la cerámica de uso doméstico (Castillo, 2013) y la arqueofauna (Araujo, 2016). El material cerámico fue estudiado en relación a los contextos particulares de uso a nivel intra-sitio, con el objetivo de analizar pautas diferenciales de consumo que remitieran a esferas de actividades domésticas, restringidas o comunitarias en su amplio sentido funcional y simbólico (Cremonte y Bugliani, 2010). El estudio del material arqueofaunístico apuntó al reconocimiento anatómico, taxonómico, de termoalteraciones, de marcas antrópicas y de procesos tafonómicos, con el objetivo de establecer la procedencia autóctona o alóctona de los animales y estudiar tendencias de procesamiento, consumo y descarte.

\section{La arqueología de la alimentación en contextos históricos de conquista}

La naturaleza fragmentaria del registro arqueológico presenta problemas en el desarrollo de una arqueología de la alimentación (Delwen, 1996). El desafío es precisamente enfrentarnos a un registro parcial e incompleto para reconstruir un sistema completo de la alimentación. El resultado final siempre será un ejercicio en pos de avanzar en la comprensión, tanto de los significados intrínsecos como de sus "superficies" (sensu Goody, 1995), considerando los desechos de cada etapa que pueden convertirse en registro de esa alimentación y sus procesos. Los análisis de estos contextos vinculados a la comida, desde una antropología de la alimentación, pueden resultar útiles para comprender los conflictos de intereses, las resistencias locales, las negociaciones y las tensiones simbólicas y económicas que se expresan en los procesos identitarios que fijan en lo culinario un operador y un lenguaje de las diferencias y la identidad (Montecino Aguirre, 2009; Montecino Aguirre y Foerster González, 2012). El comportamiento alimentario de los individuos puede ser entendido entonces, como expresiones para mantener la integración de un determinado grupo social (Herrera Flores y Götz, 2013); o como mecanismos de distinción y/o resistencia. Desde el punto de vista arqueológico, esto se ha propuesto en la región de Cuyo, por ejemplo, desde los estudios de la cerámica Viluco (Prieto Olavarría, 2012) y desde el análisis de los restos antracológicos (Mafferra, 2015). En este último caso se observó cómo la convivencia colonial puso en pugna modos de relaciones con el ambiente implicados en el modo de vida indígena y europeo, y demostró que los modos 
de resistencia se daban de forma mucho menos lineal y mucho más compleja de la prevista hasta el momento, donde la presencia o ausencia de ciertas plantas era interpretada como reproducción o resistencia de los valores implicados en la conquista (Mafferra, 2015; Marconetto y Mafferra, 2016, p.469). Esto resultaría trascendente, tanto para la construcción de la identidad de un nosotros, como en la reconfiguración identitaria dada en la articulación de las sociedades colonizadoras y colonizadas, es decir, en la relación con el otro. En este sentido, indagar el papel de la alimentación, tanto de su significado como de su "superficie" (sensu Goody, 1995), ayudaría a comprender cómo comenzó a operar el colonialismo y los mecanismos de resistencia derivados de su accionar (Dietler, 2010). Atender esa "superficie" evita desestimar el universo de la acción social (la formas particulares e históricas de cocinar y de comer), donde los significados son construidos y manipulados en el hacer mismo (Goody, 1995, p.41). Por otro lado, el comensalismo, es decir, el compartir el alimento durante su ingesta, constituye un aspecto importante como práctica social para la reproducción tanto de la unidad doméstica, como de las relaciones entre comunidades. Los individuos, al estar juntos, enmarcados por la comida y la bebida, contribuyen a la reproducción, perpetuación o al cambio de las relaciones sociales y políticas (Pollock, 2012). Dichas relaciones pueden vivenciarse alternando momentos de reproducción, perpetuación o cambio, contextualizándose en espacios y tiempos diversos. En el caso de estudio que presentamos aquí, se espera que el registro material proporcione algunas claves que den cuenta de la mixtura propia de un contexto histórico de transición hacia la conformación del mundo colonial mendocino.

La alimentación humana constituye un fenómeno complejo, dado que como expresión sociocultural atraviesa la totalidad de la actividad humana en contextos biológicos, sociales y culturales en el transcurso de su historia (Aguilar Piña, 2014). La alimentación es una actividad esencialmente social y, por ende, los modos de comer están influenciados por decisiones culturales y no solamente por necesidades nutricionales (De Garine, 1999). Las personas no sólo ingieren calorías o proteínas, más bien comen alimentos, una forma de cultura material sujeta a ilimitadas posibilidades de variación en cuestiones como ingredientes, técnicas de preparación, pautas de relación y exclusión, modos de servicio y consumo, valoraciones estéticas, entre otras. Siguiendo a Dietler (2001), podríamos considerar al alimento como "cultura material encarnada"; esto es, un tipo especial de cultura material creado específicamente para su destrucción inmediata, eliminada a través del proceso transformador de su ingestión en el cuerpo humano. Los ingredientes, las prácticas de su preparación y cocción, el equipamiento de cocina vinculado y las formas de presentar los alimentos, constituyen un todo integrado susceptible de ser abordado por la arqueología, que permite conocer las prácticas mediante las cuales se realizó un tipo de reproducción social específico (López, 2015; Marschoff, 2010; Sironi, Mafferra y López, 2015).

Los modos de alimentarse de un grupo humano pueden cristalizarse en la cocina, definida por Contreras (1992) como un fenómeno complejo en el que se involucran una gran cantidad de elementos y procesos, además de "un conjunto de reglas, de usos, de prácticas, de representaciones simbólicas y de valores sociales, morales, religiosos y sanitarios" ( $\mathrm{p}$. 67); ello, porque justamente, las cocinas poseen una dimensión étnica, nacional y/o regional. Esto supone la consideración de tres elementos centrales en su definición: un medio determinado (disponibilidad de productos alimenticios), una cultura (tecnologías de producción y preparación de alimentos dentro de un sistema social y económico determinado) y una ideología (conjunto de valoraciones ligadas a la alimentación y a su lugar dentro de la sociedad). Así, una cocina se constituye a partir de tradiciones de

El conjunto de recursos comestibles, utensilios relacionados con la alimentación, las actividades desarrolladas desde

la obtención del recurso y los contextos de comensalismo (Duke, distintas regiones y requiere un conjunto de sujetos que la reproduzcan y que le den importancia al gusto de consumir determinados alimentos. Todo este fenómeno, puede ser caracterizado con fines analíticos como un paquete culinario ${ }^{3}$. El mismo es el resultado de las formas en que los recursos han sido seleccionados, preparados y consumidos, es decir, la fuerza de trabajo aplicada sobre ellos hasta convertirlos en comida. Lo que cada sociedad 
considera como alimento no sólo tiene un correlato nutricional y de selección de un medio ambiente, sino de manera dominante un sentido simbólico: de allí las prohibiciones, los modos de consumo, las ideas sobre las propiedades de los productos que se ingieren y los principios que rigen su deglución (Duke, 2012; López, 2015; Pazzarelli, 2008).

\section{Área de estudio y contexto arqueológico}

La evidencia analizada procede del contexto PNO del punto arqueológico RSF, perteneciente al complejo jesuita que se emplazó en el año 1608 en Mendoza. Tras la expulsión de la Compañía de Jesús en 1767, el templo edificado entre los años 1716 y 1733 pasó a depender de la orden de los franciscanos en 1789 y fue destruido definitivamente con el terremoto del 20 de marzo de 1861 (Figura 1).

La ubicación del mismo en uno de los ecosistemas más aptos para el establecimiento de poblaciones que practicaron la agricultura, su cercanía a extensas áreas de humedal ubicadas a pocos kilómetros al este y las sucesivas ocupaciones detectadas a partir de los estudios arqueológicos, lo transforman en un ejemplo de caso adecuado a fines de evaluar los procesos vividos por las poblaciones indígenas y los modos de instauración del dominio colonial desde el siglo XVI hasta el siglo XVIII en el valle de Mendoza (Chiavazza, 2010; Prieto y Chiavazza, 2006, 2009a; Prieto Olavarría y Chiavazza, 2015).

En dicha intervención se recuperaron niveles correspondientes a las ocupaciones previas al terremoto, los pisos de dos templos sucesivos, los enterratorios humanos efectuados durante el periodo colonial y por debajo de estos (a dos metros y medio de profundidad), restos atribuibles a la transición entre el inicio colonial y el final de la etapa prehispánica. Concretamente, en el sector denominado Crucero se pudo registrar y datar un posible recinto habitacional correspondiente a tal período (Chiavazza, 2001; Prieto y Chiavazza, 2009a). A cinco metros de distancia en dirección noroeste, se encuentra una de las cuatro pilastras, la PNO, que sostenían la cúpula del templo jesuita. Excavado en el año 2004, presentó una secuencia continua desde la superficie hasta los $435 \mathrm{~cm}$ de profundidad, destacándose la concentración de materiales entre los $100 \mathrm{~cm}$ y los $410 \mathrm{~cm}$, donde abundan los restos cerámicos indígenas (Castillo, 2013; Prieto y Chiavazza, 2009b; Prieto Olavarría et al., 2017), acompañados por gran variabilidad y cantidad de registro arqueofaunístico y arqueobotánico (Chiavazza y Mafferra, 2007). En uno de estos niveles se obtuvo una datación por termoluminiscencia de $530 \pm 50$ AP (UCTL 1971), $1475 \pm$ 50 DC (Prieto Olavarría y Chiavazza, 2010), que corresponde a un fragmento de plato Viluco Colonial hallado entre los $290 \mathrm{~cm}$ y los $300 \mathrm{~cm}$ de profundidad que se insertaría en un contexto transicional entre el arribo español e inicios de la colonia en el territorio cuyano (Chiavazza, 2010; Prieto Olavarría y Chiavazza, 2010).

El registro arqueológico recuperado en el sector PNO fue analizado desde diversas líneas de evidencia: bioantropológica (Chiavazza, Mansegosa, Gámez Mendoza y Gianotti, 2015), cerámica (Castillo, 2013; Prieto Olavarría, 2010c, 2012; Puebla, Zorrilla y Chiavazza, 2008; Tobar, 2013), arqueofaunística (Araujo, 2016), arqueometalurgia (Quiroga, Chiavazza, Lascalea y Gurrito, 2017), arqueobotánica (Chiavazza y Mafferra, 2007; Mafferra et al., 2015), entre otras.

\section{El paquete culinario. Materiales y métodos}

\section{Los utensilios cerámicos domésticos: estado de la cuestión y metodología}

El análisis de diseños, formas y tamaños que eligieron manufacturar los alfareros del norte de Mendoza durante la dominación incaica y la colonia temprana, y el 


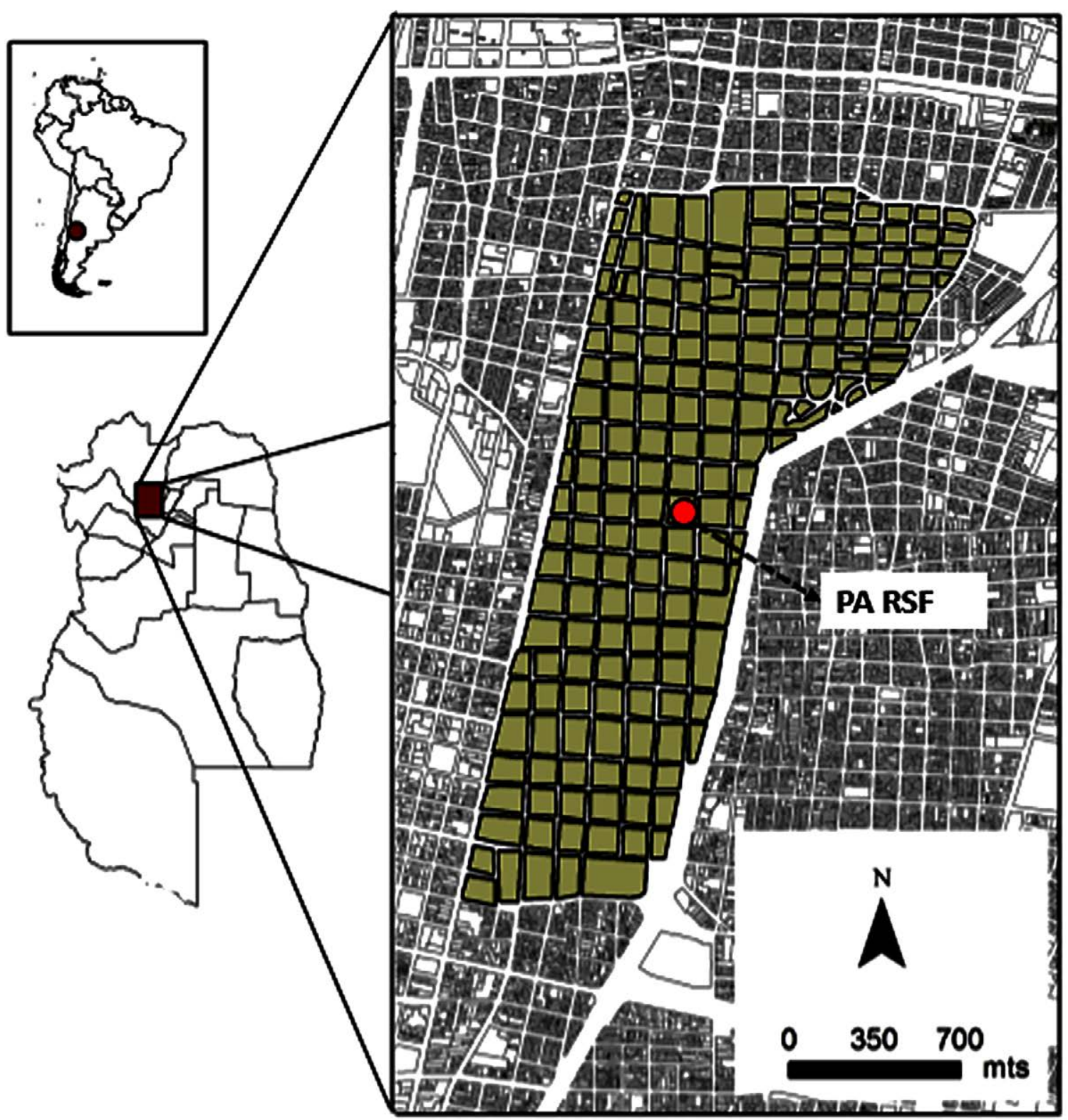

Figura 1. Ubicación del punto arqueológico RSF y el sector PNO.

conocimiento de cómo fueron utilizados en la vida cotidiana en contextos domésticos, ha sido objeto de estudios específicos (Castillo, 2013; Prieto y Chiavazza, 2009b; Prieto Olavarría, 2012; Tobar, 2013). Estos trabajos incluyeron el análisis exhaustivo de los contextos del Área Fundacional de Mendoza: Ruinas de San Francisco, Alberdi e Ituzaingó, Edificio Plaza Huarpe y La Merced (Prieto, Tobar y Castillo, 2006; Prieto Olavarría, 2010b y c, 2012; Prieto Olavarría y Páez, 2015).

La cerámica que analizamos en este trabajo se caracteriza por la ausencia de atributos tipológicos diagnósticos, como son fundamentalmente la forma y la decoración. El análisis de la producción y distribución de esta cerámica resulta de interés para indagar en aspectos de la vida cotidiana de los pobladores de un área dada en un tiempo histórico determinado (López, 2001). En este sentido, destacamos su importancia relativa frente a los tipos cerámicos considerados diagnósticos, ya que no han sido estudiados integralmente, a pesar de constituir uno de los conjuntos más abundantes 
recuperados en los contextos arqueológicos del norte de Mendoza (e.g. Bárcena y Román, 1990; Cahiza, 2001; Castillo, 2013; Lagiglia, 1976; Ots, 2007; Prieto Olavarría, 2010 b y c) $)^{4}$.

Con el objetivo puesto en comparar este conjunto cerámico con otros manufacturados en el área, se trabajó en la misma línea metodológica desarrollada para la cerámica arqueológica local (Prieto Olavarría, 2012; Prieto Olavarría y Chiavazza, 2009; Prieto Olavarría et al., 2017). La caracterización morfométrica, tecnológica, de huellas de uso y función, se basa en la propuesta de diversos autores (Cremonte y Bugliani, 2010; Falabella, Deza, Román y Almendras, 1993; González, Frère y Frontini, 2012; Orton, Tyers y Vince, 1993; Rice, 1987; Rye, 1981; Sanhueza, 1997; Shepard, 1976; Skibo, 2015; entre otros). Desde esta perspectiva, se analizaron todos los atributos de la cerámica no diagnóstica (Castillo, 2013), si bien para este trabajo nos centramos en las formas, tamaños, huellas de uso y pastas. Los atributos morfométricos de las vasijas son relevantes para definir la función, la que conjuntamente con el estudio de las huellas de uso, permiten inferir como fueron utilizados los recipientes cerámicos.

La clasificación de las formas se realizó con base en las clases estructurales y el sistema general de clasificación propuesto por Shepard (1976). Se tomaron todas las medidas posibles de ser obtenidas de los fragmentos; en el caso de los bordes, cuellos y uniones cuello-cuerpo se definió el porcentaje representado.

El análisis de las huellas de uso ${ }^{5}$ derivado de la exposición al fuego de las vasijas brinda información acerca de las técnicas de cocción empleadas. De acuerdo con Skibo (2015), la carbonización de las vasijas puede ser interna, debido al depósito de comida, o externa debido al depósito de hollín del humo producido por el fuego de cocción. La temperatura de la superficie cerámica es la variable clave en la deposición de los diferentes tipos y parches de hollín ubicados en el exterior de las vasijas. En cocciones de baja temperatura, el agua penetrará en la pared del recipiente y mantendrá la superficie cerámica relativamente fría para que se pueda depositar hollín, por ejemplo, en las ollas usadas para hervir. Por el contrario, en el caso de las ollas usadas para tostar, práctica en la que no se usa agua, la superficie cerámica alcanzará temperaturas próximas a 400 ${ }^{\circ} \mathrm{C}$ y no se depositará hollín (Skibo, 2015).

El hollín se produce por la pirolisis de la madera y está compuesto por resinas y otros productos. Los estudios experimentales (Hally, 1983, 1986; Skibo, 2015, p. 190) indican que pueden haber tres tipos de huellas de hollín en el exterior de las vasijas: 1) el hollín delgado, suave y que puede ser removido fácilmente, se halla en cualquier parte de la vasija y se adhiere inmediatamente después de que la pieza es colocada sobre el fuego; estas marcas generalmente no sobreviven a la manipulación (lavado por ejemplo) y no son usados en los estudios de alteración por uso; 2) el otro tipo de hollín más duro, se adhiere permanentemente, ya que contiene gotas de resina que se forman con el humo y se solidifican cuando entran en contacto con superficies más frías; este depósito es muy resistente al agua y a las diversas formas de bioturbación (Sassaman, 1993; Skibo, 2013, 2015); 3) marcas de fuego que no presentan hollín, ya que, aunque éste se deposite en la superficie al comenzar la cocción, luego se quema cuando está sujeto a altas temperaturas (alrededor de 400 ${ }^{\circ} \mathrm{C}$ ); este tipo de huellas puede variar de un área gris claro a otra completamente oxidada (Skibo, 2015, p. 109).

El análisis de pasta es una de las técnicas analíticas relevantes para conocer la tecnología de producción cerámica. En este caso el objetivo fue comparar las pastas de la cerámica sin atributos diagnósticos con las del tipo Viluco Inca Mixto y otros producidos localmente. Para ello se realizó el análisis macroscópico de las pastas a partir de la
4. En Castillo (2013) puede observarse un análisis de esta proporción elaborado a partir de publicaciones en diversos sitios del norte de Mendoza, dando cuenta de la asociación estratigráfica de los conjuntos.

5. En este trabajo solamente se presentan las huellas causadas por termoalteración, para más detalle ver Castillo (2013). 
observación de cortes frescos con lupa binocular (10X a 40X), sobre el 24,15\% del total de la muestra $(n=478)$ y se compararon con los patrones de pasta confeccionados para los diversos tipos cerámicos recuperados en el norte de Mendoza (Chiavazza y Prieto Olavarría, 2004; Prieto Olavarría, 2012).

\section{Los ingredientes de origen animal. Estado de la cuestión y metodología}

El estudio de la fauna recuperada en contextos arqueológicos de la ciudad de Mendoza antes del establecimiento de los conquistadores en Cuyo ha sido un tema poco estudiado. Desde el punto de vista etnohistórico se afirma que la ganadería exótica se habría diseminado por tierras cuyanas antes de la instalación efectiva de los españoles en la zona, remontando este proceso a las primeras exploraciones históricamente registradas hacia el año 1551, incluso diez años antes de la fundación jurídica de la ciudad (Prieto y Wuilloud, 1997). Los estudios arqueológicos pudieron contrastar estas afirmaciones mediante excavaciones realizadas en diversos puntos del Área Fundacional de Mendoza (Chiavazza, 2010).

Entre los antecedentes se cuenta con estudios de los restos animales recuperados en el sitio del cabildo del Área Fundacional y de las Ruinas de San Francisco (Bárcena y Schávelzon, 1992; Silveira, 1998); lo propio también, aunque específicamente desde la zooarqueología histórica se realizó en el sitio Escobería, ubicado en la manzana perteneciente a la orden de Santo Domingo (García Llorca, 2003) y por último, los resultados de las intervenciones iniciales del CIRSF, desarrolladas en distintos puntos arqueológicos del Área Fundacional: Ruinas de San Francisco, La Merced, esquinas de calles Alberdi e Ituzaingo, entre otros (Araujo, 2016; Chiavazza, 2001, 2010, 2013; Chiavazza y Prieto Olavarría, 2004; Chiavazza y Tamiozzo, 2002; Chiavazza y Zorrilla, 2006; Prieto y Chiavazza, 2009a).

En este caso, el material arqueofaunístico fue definido taxonómicamente a nivel de especie cuando fue posible. Para aquellos restos óseos de difícil identificación, se utilizaron las categorías más abarcativas de Orden, Familia y Género, según la información brindada por cada espécimen. Determinamos la procedencia de los mismos, discriminando animales autóctonos o alóctonos (procedencia euroasiática) (Araujo, 2016). Se realizó además el análisis anatómico y se estimó la abundancia relativa a partir de NISP, MNI y MNE (Mengoni Goñalons, 2010).

Se consideraron cuatro categorías de tamaño para los mamíferos según el peso promedio estimado del animal vivo: Pequeño (menos de $5 \mathrm{~kg}$ ), Mediano (entre $5 \mathrm{y}$ $50 \mathrm{~kg}$ ), Grande (entre 50 y $100 \mathrm{~kg}$ ) y Muy grande (más de $100 \mathrm{Kg}$ ) (Marschoff, 2012).

En paralelo se abordaron estudios tafonómicos considerando la fragmentación de los restos, la meteorización, la presencia de huellas naturales (raíces, evidencias de carroñeo o roedores), y principalmente las marcas producidas por el accionar humano y los grados de termoalteración que presenta la muestra (Colasurdo, 2010; FernándezJalvo y Andrews, 2016). Todos estos análisis se orientaron a determinar en primera instancia el menú disponible en el contexto estudiado, rastrear el momento del proceso de elaboración (si es que estos restos formaron parte de un alimento) y en tercera instancia establecer la técnica involucrada en dicho procedimiento para inferir las comidas de las que formaron parte los restos arqueofaunísticos (Colasurdo y Sartori, 2011; Fernández, 2010; Mengoni Goñalons, 1999). También se analizaron las astillas óseas indeterminadas (Monh, 2010).

Las cáscaras de huevo fueron identificadas, contabilizadas y medidas con el objetivo de determinar el componente de avifauna presente en el sitio (Prates y Acosta Hospitaleche, 2010). 


\section{Resultados}

\section{Características e interpretación del conjunto cerámico no diagnóstico de PNO}

El conjunto cerámico analizado constó de 1.979 fragmentos, sin incluir los que no superaban un $\mathrm{cm}^{2}$ de superficie. Asimismo, el proceso de ensamblaje permitió acotar la muestra a 1.860 fragmentos, de los cuales 167 tenían atributos de forma. Con base en estos últimos, se definió la presencia de fragmentos de vasijas correspondientes a formas restringidas y no restringidas de acuerdo a las clases estructurales propuestas por Shepard (1976), a su vez se definió la categoría correspondiente a otras formas (dos son asas, dos tienen forma de ficha y uno indeterminado) (Figura 2).

De acuerdo al sistema general de clasificación (Shepard, 1976), las vasijas restringidas de este conjunto son formas de perfil inflectado, poseen labios evertidos y las medidas de los diámetros están en los siguientes rangos: los diámetros de borde se ubican entre los 200 y $290 \mathrm{~mm}$, y los diámetros de las uniones cuello/cuerpo están entre los 150 y $250 \mathrm{~mm}$ (Tabla 1). Por su parte, las vasijas no restringidas corresponden a formas de perfil simple y sólo se pudo medir el diámetro de borde de una vasija en $250 \mathrm{~mm}$, representando el fragmento más del 15\% del borde de la pieza.

El 45\% del total de la muestra analizada $(n=822)$ presenta huellas de uso producidas por el depósito de carbón u hollín. Éstas se ubican mayoritariamente en la superficie exterior (92\%), en algunos casos poseen casi un milímetro de espesor y se caracterizan por estar fuertemente adheridas a la superficie. Las vasijas restringidas poseen huellas de hollín en el $64 \%$ de la muestra. De éstas, todos los fragmentos en los que se pudo medir el diámetro de borde y/o cuello/cuerpo presentaron huellas por termoalteración en la superficie exterior, por lo cual inferimos que dichas vasijas restringidas fueron expuestas al fuego (Figura 3). Desde esta perspectiva y siguiendo la propuesta de Skibo (2015), consideramos que estos depósitos de hollín se produjeron en labores asociadas al hervido de alimentos, ya que las superficies de las vasijas presentan gruesas y firmes capas de hollín adherido por las resinas que se forman con el humo, que se solidifican cuando entran en contacto con superficies más frías y son resistentes a la bioturbación.

Considerando los atributos morfométricos de las vasijas restringidas y del tipo de huellas de uso por depósito de hollín, es que inferimos que estas formas fueron usadas en labores de preparación de alimentos, concretamente para hervirlos. Postulamos por ello, que estas vasijas fueron usadas como ollas (siguiendo a Martínez y Heras, 1992), aunque en el estado actual de las investigaciones en el área, no contamos aún con vasijas enteras que permitan definir esta categoría con base en mayor cantidad de atributos morfométricos.

El resultado del análisis de las pastas con lupa binocular permite observar que los seis patrones representados en la cerámica no diagnóstica se encuentran presentes en la cerámica Viluco Inca Mixto ${ }^{6}$. Del total de fragmentos analizados, el 84,2\% se concentra en tres patrones: patrón $10 \mathrm{r}$ (42,4\%), patrón $11 \mathrm{r}(22,8 \%)$ y patrón $12 \mathrm{ar}(19 \%)$. El 12\% restante se divide entre los patrones $18 \mathrm{r}, 7 \mathrm{r}$ y $19 \mathrm{r}$. A partir del análisis petrográfico de láminas delgadas fue posible definir el origen geológico de las inclusiones que representan a los patrones de pasta, en este caso se denominaron familias de origen (Prieto Olavarría, 2010 a y c, 2012). Los patrones de pasta 10r y 12ar pertenecen a la familia de origen GR, en ésta predominan las rocas plutónicas graníticas (granitos y granodioritas) con un tamaño de inclusiones estimado entre 0,5 y $1 \mathrm{~mm}$. Los patrones con menor representación, el 18r y $7 \mathrm{r}$, también pertenecen a la misma familia de origen GR, variando el tamaño de sus inclusiones entre 1 y $2 \mathrm{~mm}$. El patrón $11 \mathrm{r}$ corresponde a la familia de origen $\mathrm{H}$, en la que predominan las rocas de composición heterogénea (dacitas, andesitas, basaltos) y rocas plutónicas graníticas (granitos - granodioritas)

6. Prieto Olavarría (2010a y c, 2012) definió 41 patrones de pasta correspondientes al tipo Viluco Inca Mixto y Colonial. 


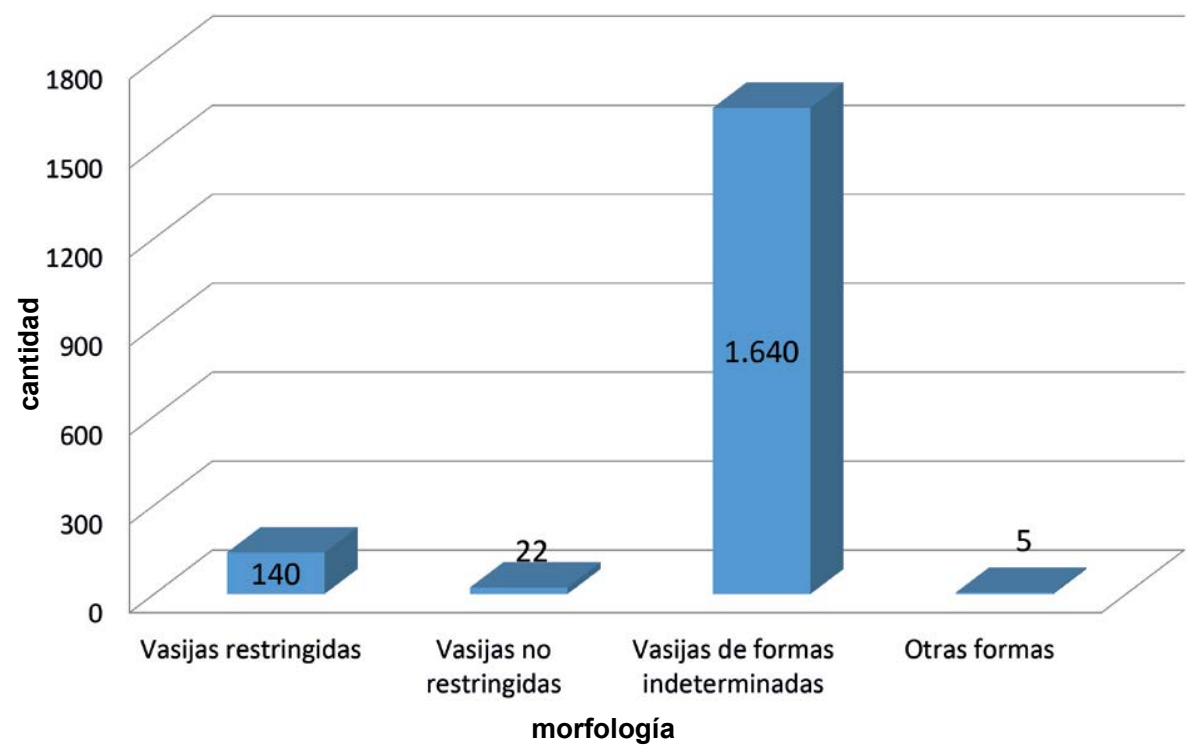

Figura 2. Distribución morfológica de los fragmentos de vasijas tras el proceso de ensamblaje.

\begin{tabular}{|c|c|c|}
\hline Vasija (ollas) & Diámetro borde $(\mathrm{mm})$ & Diámetro cuello $(\mathrm{mm})$ \\
\hline №1 & 250 & 220 \\
№2 & 250 & 230 \\
№3 & 230 & 220 \\
№4 & 280 & 250 \\
№5 & 200 & 200 \\
№6 & 290 & - \\
№7 & 279 & - \\
№8 & - & 210 \\
№9 & - & 150 \\
\hline
\end{tabular}

Tabla 1. Diámetros estimativos de nueve vasijas restringidas.

con un tamaño de las inclusiones estimado entre 1 y $2 \mathrm{~mm}$. Por último, el patrón $19 \mathrm{r}$ pertenece a la familia de origen $\mathrm{VO}$, donde dominan las rocas volcánicas mesosilícicas (dacitas y andesitas) y en menor proporción de rocas sedimentarias (areniscas cuarzosas) (Prieto Olavarría, 2010c). Se propone que las inclusiones de rocas y minerales de las pastas cerámicas de esta muestra son de origen local y provienen de las formaciones de la montaña, Cordillera Principal, Cordillera Frontal y Precordillera, las cuales son transportadas hasta la planicie a través de los principales ríos andinos (Prieto Olavarría, 2012). En el caso de los granitos, los estudios de proveniencia del material antiplástico, indican que fueron obtenidos del stock Granítico de Cacheuta (Precordillera) (Prieto Olavarría y Castro de Machuca, 2017).

Con base en los resultados obtenidos del análisis de pasta, proponemos exploratoriamente, que el acotado número de patrones representado podría evidenciar que algunas materias primas fueron consideradas más aptas que otras para la confección de las vasijas destinadas a la cocina, aunque es un aspecto a estudiar en mayor profundidad. 

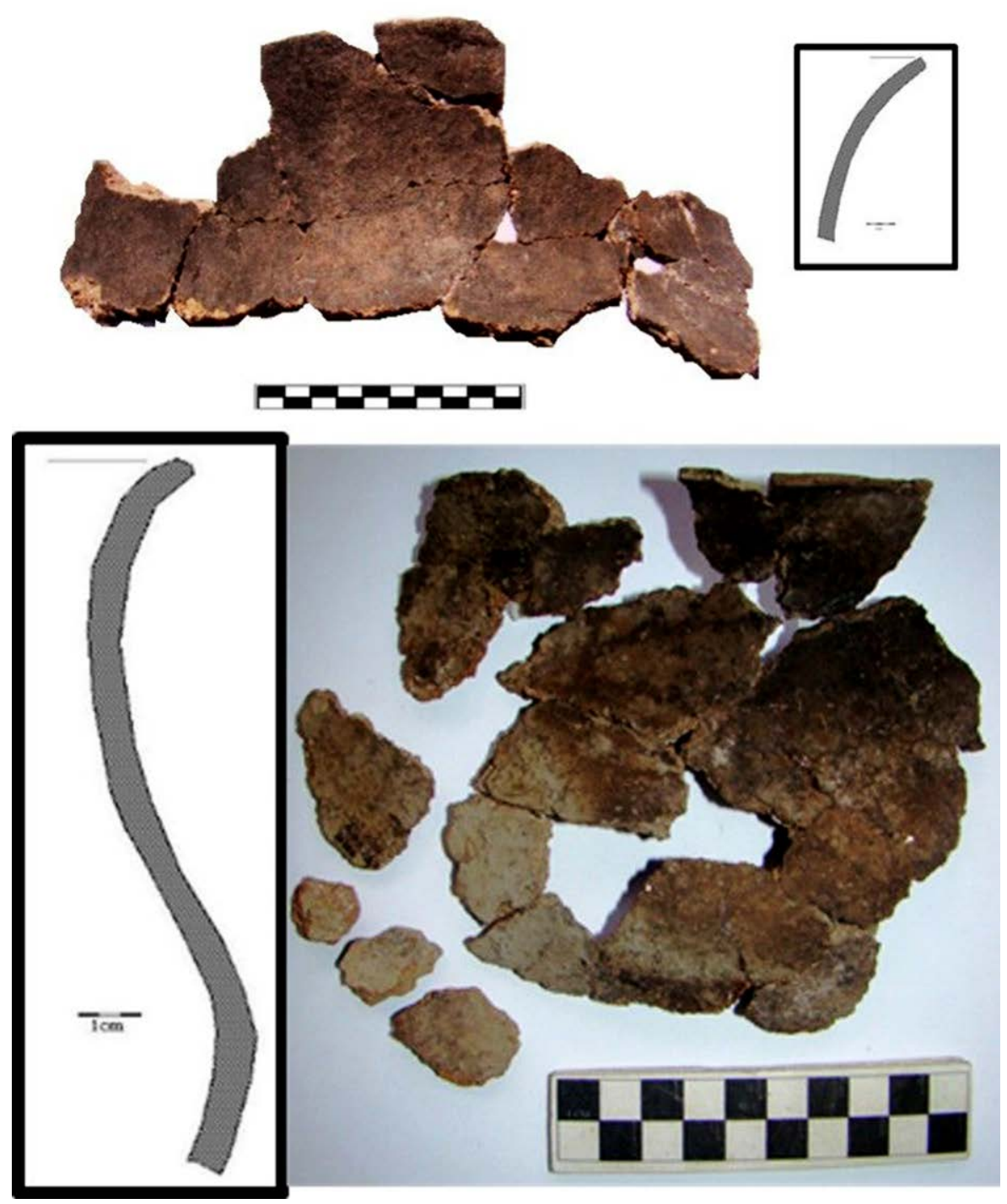

Figura 3. Dibujos de perfil e imagen de dos vasijas restringidas (ollas) con huellas de termoalteración en superficie exterior.

\section{Características del registro arqueofaunístico}

En lo que respecta al material arqueofaunístico, una superficie de seis metros cuadrados y $10 \mathrm{~cm}$ de potencia $\left(0,6 \mathrm{~m}^{3}\right)$ dio cuenta de un total de 3.769 restos, entre reconocibles, astillas y cáscaras de huevo (Tabla 2). Esta densidad de restos por $\mathrm{m}^{3}$ permite postular por el momento que se trata de una acumulación de basuras (aspectos reforzados por la posición contextual y la diversidad de materiales y estados), aunque no se descartan otros orígenes posibles (Prieto Olavarría y Chiavazza, 2015).

Los restos reconocibles (NISP) fueron 108, de los cuales 33 (30,54\%) corresponden a los animales pequeños (Gallus gallus, Zaedyus pichiy, mamífero pequeño indeterminado y ave pequeña indeterminada), 64 (59,24\%) a animales medianos (Canis familiaris, Ovis sp. y mamífero mediano indeterminado), 10 (9,25\%) a animales grandes (Lama sp., Sus scrofa y mamífero indeterminado grande) y un elemento $(0,92 \%)$ a un animal muy grande (Bos taurus). 
7. La exostosis se caracteriza por la existencia de numerosas saliencias en los huesos, sobre todo los largos y por la deformidad típica de algunos segmentos del esqueleto (Sabadotto y Mansur, 2000).

\begin{tabular}{|l|l|}
\hline \multicolumn{2}{|c|}{ Numero de restos PNO } \\
\hline NISP & 108 \\
Astillas & 3.422 \\
Cáscaras de Huevo & 239 \\
\hline NSP & 3.769 \\
\hline
\end{tabular}

Tabla 2. Número de restos animales provenientes del sector PNO (290-300 cm).
El Número Mínimo de Individuos (MNI) general establecido fue de 13 (cinco animales pequeños, cuatro medianos, tres grandes y uno muy grande). Teniendo en cuenta esta unidad cuantitativa, el 23\% de los animales que componen el registro son de procedencia autóctona (Lama sp. y Zaedyus pichiy), 46\% de procedencia europea (Ovis sp., Canis sp., Sus scrofa, Gallus gallus y Bos taurus) y el restante $31 \%$ corresponde a taxones no identificados (indeterminados).

El Número Mínimo de Elementos (MNE) fue 67, de los cuales $44 \%$ corresponden a la región axial, $44 \%$ a la apendicular y $12 \%$ al cráneo. Existen también evidencias de exostosis ósea ${ }^{7}$ en uno de los elementos (metatarso de Sus scrofa), manifestada en forma de protuberancia en su extremo distal y que podría señalar que dicho animal llegó luego de recorrer grandes distancias, este hecho apoyaría la idea de restos de animales correspondientes al periodo colonial temprano.

La muestra reconocible presenta altos grados de fragmentación, con un $13,88 \%$ de elementos completos y el resto fragmentado, aunque con un bajo grado de meteorización, el 66\% de la muestra presenta un estado de 1 según la escala de Behrensmeyer (1978). Los principales agentes naturales detectados fueron marcas producidas por dientes de carnívoros en tres huesos y huellas de raíces en otros siete, pero ambas afectaron a un reducido $9 \%$ de la muestra total.

Las evidencias de fracturas en general se encontraron asociadas con agentes antrópicos siendo en su mayoría transversales regulares y transversales irregulares asociadas a marcas de corte. Estas marcas se presentan en su mayoría en forma transversal al eje del hueso y se detectaron en 21 restos $(19,44 \%)$ de la muestra reconocible. De este total el $85,8 \%$ de los restos fueron afectados con cortes correspondientes a filos agudos, el $9,5 \%$ a marcas de hachuela, $4,7 \%$ a marcas de raspado.

El 80\% de las marcas se registraron en los huesos de animales medianos (Ovis sp. y mamífero indeterminado) en 10 restos correspondientes a costillas y encontrándose asociados a fracturas transversales regulares de marcado perimetral completo (Figura 4).

Sólo un 8,3\% de la muestra de elementos reconocibles presentó signos de termoalteración: seis fragmentos tostados correspondientes a placas y escudos escapulares de Zaedyus pichiy, dos carpos (uno de Ovis sp. y el otro de una pequeña ave indeterminada) han sido quemados y un carpo de Ovis sp. totalmente calcinado. Los demás restos $(91,7 \%)$ no presentan signos de termoalteración.

En lo que respecta a las astillas, el número total fue de 3.422 y en su mayoría corresponden a animales de tamaño mediano o grande (96,5\%). Sólo el 3,5\% corresponde a animales pequeños, siendo las mismas difíciles de asignar a algún taxón. El 65\% del total pudo ser asignado al orden Mammalia, un 34\% a indeterminados y un $1 \%$ a aves. Del total, 481 astillas pudieron ser adscriptas a una determinada región anatómica: 212 restos al esqueleto apendicular, 207 al axial y 62 al cráneo. El grado de fragmentación en este 


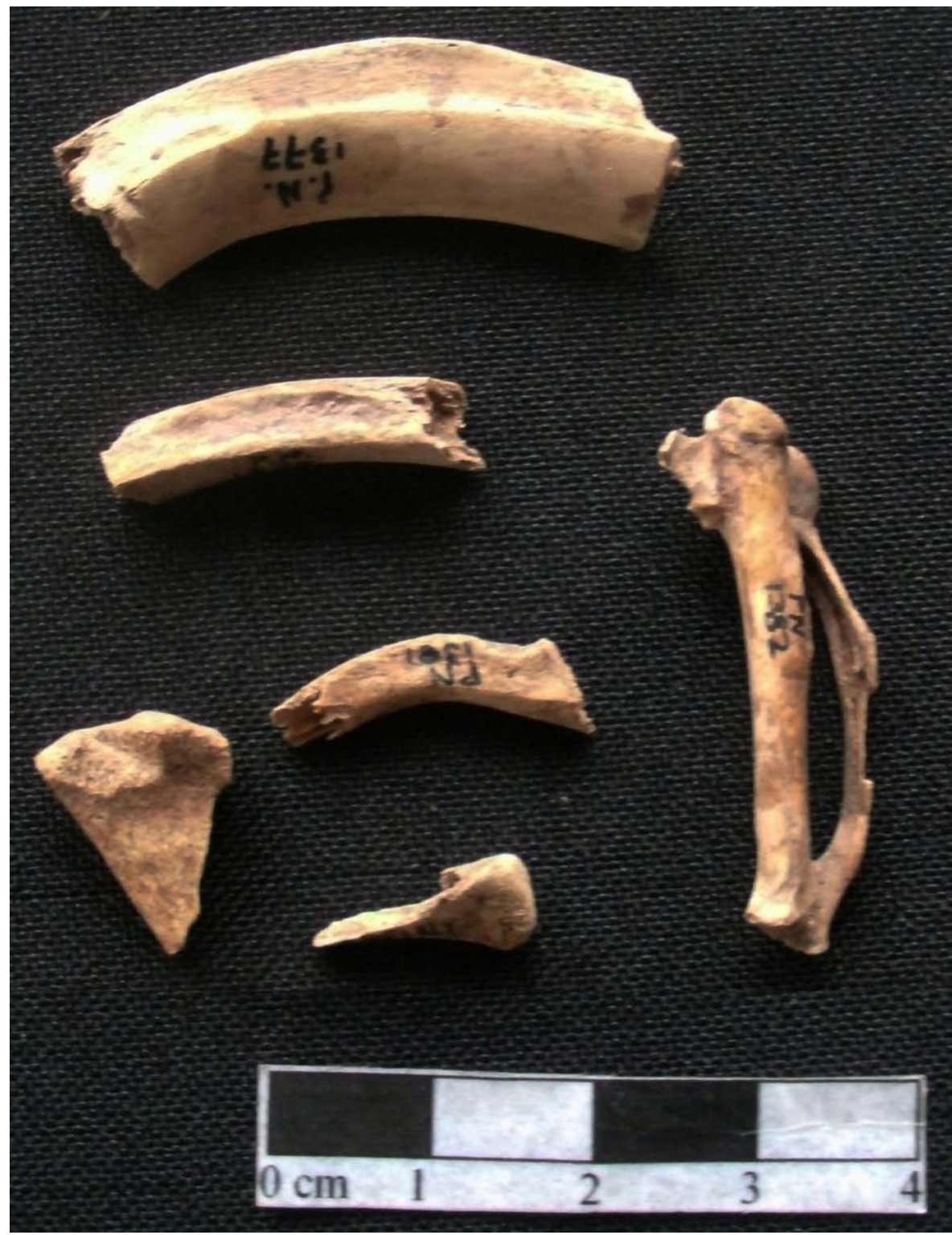

Figura 4. Algunos restos arqueofaunísticos del sector PNO. Arriba, cuerpo de costillas de mamífero indeterminado con evidencias de fractura intencional. A la derecha, metacarpo de Gallus gallus.

sentido es alto, ya que el $80 \%$ correspondió a astillas que no superaron el centímetro de largo, y solo el $20 \%$ se encuentra entre el centímetro y los dos centímetros. La termoalteración tuvo escasa representación en las astillas, al igual que en la muestra de óseos reconocibles, con 7,8\% (193 calcinados, 86 quemados, 15 quemados calcinados y uno tostado) existiendo una considerable mayoría $(92,2 \%)$ de restos sin evidencias de termoalteración alguna. A nivel de observación macroscópica no se registraron marcas de corte en ninguna astilla, aunque el patrón de fractura en las más grandes es similar al registrado en el material óseo reconocible: transversal regular e irregular, con un alto porcentaje de astillas fracturadas de manera longitudinal.

Finalmente, las cáscaras de huevo estuvieron representadas por un total de 239 fragmentos. El 10\% de la muestra (24 fragmentos) pudo ser asignado a Rheidae, aunque el tamaño inferior al $\mathrm{cm}^{2}$ de estos restos imposibilitaron la determinación de especie. El restante 90\% (215 fragmentos) corresponde a ave indeterminada. La fragmentación 
también es alta debido a que solamente 23 elementos superan los $0,5 \mathrm{~cm}^{2}$. Las cáscaras termoalteradas representan el $3 \%$ de la muestra (siete cáscaras tostadas, una quemada y una calcinada).

\section{Discusión}

Para caracterizar el paquete culinario, estructuramos los resultados antes expuestos siguiendo las actividades concatenadas correspondientes al proceso involucrado en la cocina, procurando integrar ambas líneas de evidencia material: obtención, producción y distribución, preparación y cocción, presentación y consumo.

\section{Obtención, producción y distribución}

A partir del ingreso incaico y luego de la implantación colonial, entre los siglos XV y XVII, los alfareros locales incorporaron nuevas técnicas, formas y decoraciones en la producción de las vasijas, utilizando para ello materias primas de procedencia local (Prieto Olavarría, 2012). En este contexto, la alfarería Viluco y la no diagnóstica, sintetizaron las tradiciones cerámicas en constante transformación. La cerámica Viluco Inca Mixto operó en la construcción de la identidad local, ya que cumplió la función de mediador visual en las relaciones sostenidas entre las jerarquías políticas locales y entre éstas y los dominadores (Prieto Olavarría, 2010b; Prieto Olavarría y Chiavazza, 2015; Prieto Olavarría y Páez, 2015; Tobar, 2013; entre otros). Por su parte, la presencia de un conjunto no diagnóstico usado para cocinar y asociado al tipo Viluco Inca Mixto, refleja un aspecto en que las poblaciones locales se desenvolvieron en el ámbito doméstico en el contexto de la implantación de nuevos sistemas económicos, cuando nuevas identidades indígenas se encontraban en proceso de reconfiguración y donde los modos de consumo y de comer operaron activamente.

El análisis de restos arqueofaunísticos correspondientes a tiempos transicionales, inmediatamente previos y posteriores a la fundación de la ciudad en el año 1561, pudo establecer que en el valle de Güentata existió una relativa variedad de animales susceptibles de ser empleados como ingredientes cárnicos en las preparaciones de sus pobladores. Los animales disponibles representados en el registro fueron el guanaco o llama (Lama sp.), el piche (Zaedyus pichiy) y alguna o ambas variedades de ñandú o choique (Rheidae), representadas en las cáscaras de huevo, que fueron los exponentes de la fauna local; mientras que la vaca (Bos taurus), el cerdo (Sus scrofa), el ovino (Ovis sp.), el cánido (Canis sp.) y la gallina (Gallus gallus), constituyeron las especies representantes de la fauna europea. Los mecanismos de obtención de estos animales podrían haber incluído la caza, la pesca y la captura, así como también el comercio con los residentes en Chile (Prieto y Willoud, 1997), las actividades pastoriles de los mismos grupos huarpes (prácticas incorporadas antes de la instalación efectiva de los españoles) (Chiavazza, 2010; Prieto y Willoud, 1997), como obsequios de los conquistadores a los grupos indígenas (Prieto y Willoud, 1997), o como sugieren algunos autores para la zona de sierras centrales, a través del robo como forma de apropiación de la fauna europea por parte de los grupos indígenas (Pastor y Medina, 2013).

\section{Preparación de los alimentos. De la carta a la tabla}

A partir de los análisis y caracterización de marcas antrópicas en los huesos, puede constatarse el empleo de por lo menos ocho taxones en las comidas de las sociedades cuyanas del periodo estudiado. Gallus gallus, Ovis sp., Lama sp., Zaedyus pichiy, Sus scrofa y Bos taurus habrían constituído los recursos carnícos empleados para las preparaciones culinarias, que fueron procesados mediante una serie de instrumentos de filo (líticos o metálicos) y también de hachas (las marcas de hacha en algunos de 
estos restos corroboran su uso descriptos por algunos documentos para el siglo XVII) (García Llorca 2003, 2009; Marschoff, 2010; Silveira, 2005).

Entre la diversidad de restos se advierte el faenamiento tanto de animales locales como europeos, resaltando Ovis sp. Al tiempo que, mamíferos y aves indeterminados también registraron marcas de los distintos tipos. El procesamiento de estos animales incluyó la reducción intencional de algunos de sus huesos, como costillas y elementos de la región apendicular, evidenciado en cortes transversales regulares y en una alta fragmentación, y apoyada por el dato de los astillajes. Este hecho estaría vinculado a la noción de pot sizing o achicamiento antrópico de partes esqueletales con formas complicadas (vértebras y costillas) para poder incorporarlos en los recipientes cerámicos que oficiarían de intermediarios para su cocción y permitirían la obtención de carne residual (Izeta, Srur y Silva, 2013; López, 2015).

\section{Cocción de los alimentos. De la tabla a la olla}

En la cocción de los alimentos pudo identificarse la preminencia de tradiciones locales que estarían caracterizadas por dos mecanismos: el hervido y el asado. Los restos de ingredientes cárnicos afectados por la acción del fuego directo representan el 8,3\% de la muestra, mientras que la alta fragmentación, la reducción intencional y la ausencia de evidencias de termoalteración en el 91,7\% restante, indicaría al hervido como mecanismo de cocción más generalizado en la muestra.

El hervido, como técnica de cocción, a diferencia del asado, necesita de un objeto cultural "real", en este caso, la vasija, que a su vez actúa también en una dimensión "simbólica", como mediadora entre el alimento y el fuego (sensu Lévi-Strauss, 2010 [1964]). Así, el empleo de esta técnica quedó evidenciado tanto en el registro arqueofaunístico como en las características morfométricas y las huellas de hollín que están presentes en los fragmentos de las vasijas restringidas y que interpretamos fueron usadas como ollas para hervir los alimentos. Estas ollas son las formas más representadas en el registro de la cerámica no diagnóstica y habrían sido usadas para procesar aquellos ingredientes que requieren largos períodos de hervido para lograr su palatabilidad. Esta tendencia se correlaciona con las propuestas derivadas del estudio de información documental, etnográfica y/o arqueológica disponible para el área Andina, donde Bray $(2003,2004)$, mediante la vinculación del análisis de crónicas y de las vasijas incas más frecuentes encontradas en la capital y las provincias, afirma que el hervido y el tostado son las técnicas más recurrentes en los Andes incaicos. Por su parte, y desde una perspectiva antropológica, diversos autores han demostrado la identificación del hervido como una técnica de cocción ligada a una tradición específicamente andina (Laguens et al., 2007; Pazzarelli, 2010, 2011; Weismantel, 1994).

\section{Presentación y consumo de las comidas. De la olla a la mesa}

En esta etapa del paquete culinario, la alfarería que entra en escena se vincula con los tipos definidos como diagnósticos y se encuentran representados el Viluco Inca Mixto, relacionado con la influencia y la dominación incaica, y el Viluco Colonial, relacionado con la influencia y dominación española (Prieto Olavarría, 2012; Prieto Olavarría y Chiavazza, 2015; Prieto Olavarría et al., 2017). Las formas definidas para el tipo Viluco Inca Mixto son jarras pequeñas, escudillas y posiblemente aribaloides y keros, mientras que para el tipo Viluco Colonial se debe hablar de platos. La asociación contextual de los tipos diagnósticos Viluco y la cerámica de uso doméstica y no decorada, nos permite indagar acerca del rol de los objetos en las prácticas sociales. El objeto, en este caso una vasija, asume un carácter mediador entre las personas, como mercancía y como índice de status social (Baudrillard, 1994). Los objetos, ya sean considerados diagnósticos o no diagnósticos, acompañan, hacen posible o facilitan las prácticas 
sociales. En este sentido, las vasijas Viluco habrían cumplido el rol de mediadores visuales dentro de los grupos locales, así como entre estos y los dominadores incas y españoles (Prieto Olavarría, 2012; Prieto Olavarría y Chiavazza, 2015; Tobar, 2013). El tipo Viluco Inca Mixto posee atributos decorativos y tecnológicos (por ejemplo, el uso de inclusiones piroclásticas en las pastas) que no están presentes en las vasijas de uso doméstico relacionadas con la elaboración de alimentos (Prieto Olavarría y Páez, 2015). Estas características, más las huellas de uso y los contextos de hallazgo, permitieron definir que esta cerámica fue usada para servicio y sobre todo, para la presentación de la comida, como contenedores de sólidos o líquidos, probablemente en contextos vinculados al ámbito de lo ritual, del poder y lo político (Prieto Olavarría, 2012). En estos contextos, su visibilidad y la de sus símbolos adquirieron la fuerza de la historia que los precedió y configuró.

De los ingredientes se puede decir que la carne de ovino, tan apetecida por los españoles de la época (Marschoff, 2010), encontraría un correlato material en el contexto desde momentos muy tempranos (en este trabajo hemos puesto en consideración los restos más antiguos de esta especie datados en la región). Si bien es cierto que las razones por las cuales tuvo tanto éxito este animal respondieron a las capacidades adaptativas al medio ambiente (Prieto y Willoud, 1997), no perdemos de vista el sentido social o político, al igual que en el caso de la cerámica Viluco, que pudo haber tenido la incorporación de un ingrediente europeo en las comidas de tradición local.

\section{Conclusiones}

Con todo lo visto anteriormente, se puede establecer en primer lugar que el sector PNO de RSF correspondió, para los niveles datados entre los siglos XV y XVII, a un contexto material vinculado con la cocina y/o con el descarte de las actividades propias de ella. Las evidencias indicarían el predominio del hervido como técnica de cocción, modalidad que ha sido asociada a la tradición andina y que habría sido aplicada a ingredientes tanto locales como no locales.

Esta vinculación estaría confirmada a través de cuatro tipos de relaciones materiales: a) mayor cantidad de restos de alfarería no diagnóstica $(\mathrm{n}=1.860)$ de manufactura local que habrían sido utilizadas en actividades domésticas relacionadas con la cocción de alimentos. Esta abundante presencia contrasta con los tipos diagnósticos Viluco (n $=1.504$ ), cuya función estaría destinada a la última etapa de las prácticas culinarias relacionadas con el consumo y el servicio; b) elementos óseos con evidencias de manipulación antrópica conformado por un $23 \%$ de animales de procedencia autóctona (local), un $46 \%$ de procedencia europea (no local) y el restante $31 \%$ corresponde a taxones no identificados; c) la relación entre la presencia de ollas cerámicas con evidencia de haber sido usadas para hervir alimentos y las evidencias de fragmentación/ achicamiento (pot sizing) en huesos de animales medianos, grandes y muy grandes; d) una relación inversamente proporcional en las evidencias de termoalteración de las ollas y los restos óseos de fauna, sugiriendo al hervido como técnica de cocción practicada.

La materialidad de la cocina puede indicar algunos aspectos de los modos de alimentarse que tuvieron los habitantes de esta región, reflejando tempranos y complejos procesos de interacción. Utilizando como marco el proceso analítico propuesto por Contreras (1992), nuestros análisis pudieron dar cuenta, en primer lugar, del medio, donde explicitamos el menú disponible, que para el caso del valle de Güentata consistió tanto en animales de procedencia local (es decir autóctona) como no local (europea) en tiempos donde se vivían procesos de interacción biológica y cultural intensos, como fue el avance y la conquista española sobre el sustrato de una anterior conquista y dominación incaica entre los siglos XV y XVI. El segundo elemento central de la 
cocina es la presencia de una cultura, materializada en las tecnologías de producción y preparación de alimentos dentro de un sistema social y económico determinado. En este caso indagamos en las vasijas, sus formas y técnicas de manufactura, así como en la conformación de la dieta y el procesamiento de los ingredientes escogidos dentro del menú disponible.

Coincidimos además en la existencia de un tercer elemento en la cocina, que es la marca de una ideología. Las relaciones materiales establecidas anteriormente para el contexto doméstico del sector PNO permiten aproximarnos al conjunto de prácticas ligadas a la alimentación, ubicándose en un lugar de privilegio en los contextos de reproducción social, dotados de significativa importancia en momentos de transición y de choque cultural. Como hemos visto hasta aquí, el sistema alimentario es habitualmente el resultado de una historia de cambios y continuidades, de inclusión y exclusión de nuevos productos alimenticios y recetas, de rearticulación y transformación de las ideologías nutricionales y por ende de lo que se debe y no se debe comer. Por ello, nos interpela en términos de estructuras, pero también de procesos, y de ahí que su elucidación convoque una multiplicidad de ámbitos que anudan lo somático con lo social de manera irrevocable.

Finalmente pensamos que estos resultados pueden constituirse en una plataforma que permita indagar en la integración de diversas líneas de evidencia material (estructuras de combustión, fogones o espacios concretos de cocción, restos botánicos, antracológicos y líticos, entre otros) y establecer sus relaciones contextuales, con el objetivo de alcanzar una modelización de posibles contextos domésticos en sitios de gran complejidad, especialmente sobre aquellos niveles arqueológicos correspondientes al período de contacto entre colonos y nativos bajo la emergencia urbana implantada. La integración de estas líneas de análisis, sumado a la evidencia etnográfica y etnohistórica disponible para el Centro Oeste Argentino, permitirá aproximarnos a ciertas prácticas de alimentación y patrones de comensalismo en tiempos de conquista, en vistas de lograr una comprensión más ajustada de sus posibles sentidos, no sólo ya del Valle de Güentata, sino también de la periferia cultural del área.

\section{Agradecimientos}

A los colegas del CIRSF del Área Fundacional, a la Municipalidad de Mendoza; a CONICET; al Foncyt, a la Agencia de Promoción Científica y Tecnológica Nacional y a la Facultad de Filosofía y Letras de la UNCuyo. A los evaluadores del presente artículo que contribuyeron con sus críticas y aportes a enriquecer el texto y a sus autores. 


\section{Referencias citadas}

" Aguilar Piña, P. (2014). Cultura y alimentación. Aspectos fundamentales para una visión comprensiva de la alimentación humana. Anales de Antropología, 48(1), 11-31.

"Araujo, E. (2016). Modos de comer y culturas en transición. Análisis arqueofaunístico de un contexto doméstico de los siglos XV-XVI de la ciudad de Mendoza (Punto Arqueológico Ruinas de San Francisco). (Tesis de Licenciatura inédita), Universidad Nacional de Cuyo, Argentina.

" Arnold, D. (2000). La naturaleza como problema histórico: El medio, la cultura y la expansión de Europa. Madrid: Fondo de Cultura Económica de España.

" Bárcena, J. R. (1988). Investigación de la dominación incaica en Mendoza. El tambo de Tambillos, la vialidad anexa y los altos cerros cercanos. Espacio, tiempo y forma, Serie I Prehistoria, I, 397-426.

» Bárcena, J. R. (2005). Avances 2002/2003 sobre el conocimiento arqueológico y etnohistórico de la dominación en el Centro Oeste Argentino, extremo austral oriental del Tawantinsuyu. Xama, 15-18, 119-149.

» Bárcena J. y Román, A. (1990). Funcionalidad diferencial de las estructuras del tambo de Tambillos: resultados de la excavación de los recintos 1 y 2 de la Unidad A del Sector III. Anales de Arqueología y Etnología, 41-42, 7-81.

" Bárcena, J. R. y Schávelzon, D. (1992). El Cabildo de Mendoza. Arqueología e Historia para su recuperación. Xama, 2, 1-174.

" Barth, F. (1976). Los grupos étnicos y sus fronteras. La organización social de las diferencias culturales. México D. F.: Fondo de Cultura Económica.

"Bartolomé, M. A. (2006). Procesos interculturales: antropología política del pluralismo cultural en América Latina. México D. F.: Siglo XXI.

" Baudrillard, J. (1994). El Sistema de los Objetos. México D. F.: Siglo XXI.

» Behrensmeyer, A. (1978). Taphonomic and ecological information from bone weathering. Paleobiology, 4(2), 150-162.

» Braudel, F., (1992). The Perspective of the World. Civilization and Capitalism $15^{\text {th }}-18^{\text {th }}$ Century, (Volumen 3). Berkeley: University of California Press.

" Bray, T. (2003). To Dine Splendidly. Imperial Pottery, Comensal Politics, and the Inca State. En T. Bray (Ed.), The Archaeology and Politics of Food and Feasting in Early State and Empires, (pp. 93-142). New York: Kluwer Academic/Plenum Publishers.

" Bray, T. (2004) La alfarería imperial inka: una comparación entre la cerámica estatal del área del Cuzco y la cerámica de las provincias. Chungara. Revista de Antropología Chilena, 36(2), 365-374.

"Cahiza, P. (2001). Problemas y perspectivas en el estudio de la dominación inca en las tierras bajas de Mendoza y San Juan: el sitio Torre 285, Retamito. Xama, 12-14, 173-197.

»Cahiza, P. y Ots, M. J. (2005). La presencia inka en el extremo sur oriental del Kollasuyo. Investigaciones en las tierras bajas de San Juan y Mendoza, y el Valle de Uco -Rca. Argentina. Xama, 15-18, 217-228.

"Canals Frau, S. (1946). Etnología de los Huarpes. Anales del Instituto de Etnología Americana, VII, 9-147. 
»Castillo, L. (2013). Alfarería Indígena de Uso Doméstico en el Predio Ruinas de San Francisco del Área Fundacional de Mendoza. Mendoza: Publicaciones del CIRSF. Editorial de la facultad de Filosofía y letras, Universidad Nacional de Cuyo.

»Chiavazza, H. (2001). Estudios arqueofaunísticos en el Área Fundacional de Mendoza. Manuscrito inédito.

»Chiavazza, H. (2010). Procesos sociales y ambientales en el sector urbano de Mendoza entre los siglos XV-XVIII: Arqueología urbana e historia Ambiental. Comechingonia Virtual, 4(2), 227-253.

»Chiavazza, H. (2012). Procesos Sociales y ambientales en el sector urbano de Mendoza entre los siglos XV-XVIII (PSYAU II): Tecnología y Subsistencia en contextos de transformación. Informe SeCTyP, Universidad Nacional de Cuyo, Mendoza. Manuscrito inédito.

»Chiavazza, H. (2013). No tan simples: Pesca y horticultura entre grupos originarios del norte de Mendoza. Comechingonia Virtual, 1, 27-45.

»Chiavazza, H. y Mafferra, L. (2007). Estado de las investigaciones arqueobotánicas en Mendoza y sus implicancias en la arqueología histórica. Revista de Arqueología Histórica Argentina y Latinoamericana, 1, 127-152.

»Chiavazza, H., Mansegosa, D., Gámez Mendoza, A. y Gianotti, S. (2015). Funebria católica y estimaciones del sexo y de la edad en entierros de una ciudad americana colonial (Mendoza, Argentina). Revista de Arqueología Histórica Argentina y Latinoamericana, 9(1), 35.

»Chiavazza, H. y Prieto Olavarría, C. (2004). Arqueología en el predio jesuita de la antigua ciudad de Mendoza-Centro Oeste Argentino. Trabajo presentado en el X Congreso Nacional de Arqueología Uruguaya. Montevideo, Uruguay.

»Chiavazza, H. y Tamiozzo, B. (2002). Arqueología a la vuelta de la esquina: excavaciones en la esquina de Alberdi e Ituzaingo. En D. Schávelzon (Ed.), Arqueología Histórica Argentina. Actas del Primer Congreso Nacional de Arqueología Histórica Argentina (pp. 131-144). Buenos Aires: Corregidor.

»Chiavazza, H., y Zorrilla, V. (Eds.). (2006). Arqueología en el predio mercedario de la ciudad de Mendoza. Mendoza: Editorial de la Facultad de Filosofía y Letras, Universidad Nacional de Cuyo.

»Colasurdo, M. B. (2010). Inferencias de consumo en un sitio histórico de la ciudad de Rosario a partir de los restos arqueofaunísticos. En M. Berón, L. Luna, M. Bonomo, C. Montalvo, C. Aranda y M. Carrera Aizpitarte (Eds.), Mamül Mapu. Pasado y presente desde la arqueología pampeana (pp. 215-230). Buenos Aires: Libros del Espinillo.

»Colasurdo, M. B. y Sartori, J. I. (2011). La conformación de la etnicidad a partir de los hábitos alimenticios: su abordaje desde la antropología y la arqueología histórica. Revista de Arqueología Histórica Argentina y Latinoamericana, 5, 125-146.

»Contreras, J. (1992). Alimentación y Cultura: reflexiones desde la antropología. Revista Chilena de Antropología, 11, 95-111.

»Cremonte, M. B. y Bugliani, M. F. (2010). Pasta, Forma e Iconografía. Estrategias para el Estudio de la Cerámica Arqueológica. Xama, 19-23, 239-262.

"Crosby, A. W. (1988). Ecological Imperialism: the overseas migration of western Europeans as a biological phenomeno. En D. Worster (Ed.), The ends of the earth (pp. 103-117). Cambridge: Cambridge University Press.

»De Garine, I. (1999). Antropología de la alimentación, entre la naturaleza y la cultura. Conferencia inaugural. En Actas del Congreso Internacional de Alimentación y Cultura (pp. 13-34). Huesca: La Val de Onsera. 
》Delwen, S. (1996). Approches to the Archaeology of Food. Petits Propos Culinaires, 54, 12-21.

»Dietler, M. (2001). Theorizing the feast: rituals of consumption, commensal politics, and power in African contexts. En M. Dietler y B. Hayden (Eds.), Feasts: Archaeological and Ethnographic Perspectives on Food, Politics, and Power (pp. 65-114). Washington: Smithsonian.

»Dietler, M. (2010). Cocina y colonialismo. Encuentros culinarios en la Francia mediterránea protohistórica. Sagvntvm Extra, 9, 11-26.

»Dillehay, T., Williams, V. y Santoro, C. (2006). Áreas periféricas y nucleares. Contextos de interacciones sociales complejas y multidireccionales. Chungara. Revista de Antropología Chilena, 38(2), 249-256.

»Duke, G. (2012) Consuming Identities: Culinary Practices in the Late Moche Jequetepeque Valley, Peru. Trabajo presentado en el $77^{\circ}$ Annual Meeting of the Society for American Archaeology, Memphis, USA.

» Falabella, F., Deza, A., Román, A. y Almendras, E. (1993). Alfarería Llolleo: un enfoque funcional. Boletín № 4 Museo Regional de la Araucanía, II, 327-353.

» Fernández, P. (2010). Cazadores y Presas. 3500 años de interacción entre seres humanos y animales en el noroeste de Chubut. Buenos Aires: Fundación de Historia Natural Félix de Azara.

» Fernández-Jalvo, Y. y Andrews, P. (2016). Atlas of Taphonomic identifications. Springer: Dordrecht.

"García A. E. (1999). Alcances del dominio incaico en el extremo suroriental del Tawantinsuyu. Chungara. Revista de Antropología Chilena, 29(2), 195-208.

» García Llorca, J. (2003). Avances en los estudios zooarqueológicos del sitio Escobería, en la manzana de Santo Domingo, Ciudad de Mendoza. Relaciones de la Sociedad Argentina de Antropología, XXVIII, 133-152.

» García Llorca, J. (2009) El uso de la sierra metálica en contextos históricos urbanos. Análisis del sondeo I en el distrito Pedro Molina, Guaymallén, Mendoza. Arqueología, $15,149-164$.

» González, M. I., Frère, M. M. y Frontini, R. (2012). Formas de ollas de cerámica pampeana y consumo de alimentos. En M. P. Babot, M. Marschoff y F. Pazzarelli (Eds.), Las manos en la masa: arqueologías, antropologías e historias de la alimentación en Suramérica, (pp. 405-425). Córdoba: Museo de Antropología, Facultad de Filosofía y Humanidades, Universidad Nacional de Córdoba.

» Goody, J. (1995). Cocina, cuisine y clase. Estudios de sociología comparada. Barcelona: Gedisa.

» Hally, D. J. (1983). Use alternation of pottery vessel surfaces: An important source of evidence for the identification of vessel function. North American Archaeologist, 4, 3-26.

» Hally, D. J. (1986). The identification of vessel function: a case study from Northwest Georgia. American Antiquity, 51(2), 267-295.

» Harris, M. (2011). Bueno para comer. Madrid: Alianza Editorial.

» Herrera Flores, D. A. y Götz, C. (2014). Estudios la alimentación de los antiguos mayas de la península de yucatán: consideraciones sobre la identidad y la cuisine en la época prehispánica de cultura maya. Estudios de Cultura Maya, 43, 69-98.

» Izeta, A., Srur, M. ySilva, T. (2015). Huesos Fragmentados: algunas consideraciones acerca de desechos culinarios y de formatización de instrumentos. En M. P. Babot, M. Marschoff y F. Pazzarelli (Eds.), Las manos en la masa: arqueologías, antropologías e historias de la alimentación en Suramérica, (pp. 463-505). Córdoba: Museo de Antropología, Facultad de Filosofía y Humanidades, Universidad Nacional de Córdoba. 
» Lagiglia, H. (1976). La Cultura de Viluco del Centro Oeste Argentino. Revista del Museo de Historia Natural, III(1-4), 227-265.

» Laguens, A., Dantas, M., Figueroa, G., Gastaldi, M., Juez, S. y Pazzarelli, F. (2007). Vasijas + Pucos con huesos + Agua no son solo sopa: La cerámica de uso doméstico en el Siglo $\mathrm{XI}$ d.C. en el valle de Ambato, Catamarca y sus relaciones con otros entramados sociales y materiales. Pacarina (Número Especial), II, 353-359.

» Lévi-Strauss, C. (2010) [1964]. Mitológicas I. Lo crudo y lo cocido. México D. F.: Fondo de Cultura Económica.

» López, M. A. (2001). Los núcleos de cocción en las pastas cerámicas arqueológicas, indicadores y variables relacionados con algunos aspectos de la secuencia de producción. Xama, 12-14, 133-149.

» López, M. L. (2015). Prácticas culinarias como medio para la reproducción social de los grupos prehispánicos de las sierras de Córdoba. En J. Salazar (Ed.), Condiciones de posibilidad de la reproducción social en sociedades prehispánicas y coloniales tempranas en las Sierras Pampeanas (Argentina) (pp. 177-213). Córdoba: Centro de Estudios Históricos Prof. Carlos Segreti.

» Mafferra, L. (2015). Arqueología de los paisajes forestales del norte de Mendoza. (Tesis Doctoral inédita), Universidad Nacional de Córdoba, Argentina.

» Mafferra L., Chiavazza, H. y Roig, F. A. (2015). El árbol que da frutos se corta y se echa al fuego. Discusiones sobre el uso de la leña en la Mendoza colonial. Comechingonia. Revista de Arqueología, 19(2), 203-234.

» Marconetto, B. y Mafferra, L. (2016). Todos los fuegos el fuego: Discusión en torno a las categorías modernas en la interpretación de registros antracológicos en contextos prehispánicos y coloniales. Cadernos do Lepaarq, XIII(25), 459-483.

》 Marschoff, M. (2010). Sociabilidad y Alimentación. Estudio de casos en la transición al siglo XIX en el Virreinato del Río de la Plata. (Tesis Doctoral inédita), Universidad de Buenos Aires, Argentina.

» Marschoff, M. (2012). Dando uso a los "indeterminados": un marco de referencia específico para la zooarqueología de contextos históricos hispanocriollos. Archaeofauna, 21, 175-193.

» Martínez y Heras, C. (1992). Glosario terminológico para el estudio de las cerámicas arqueológicas. Revista de Antropología Americana, 22, 8-34.

» Mengoni Goñalons, G. (1999). Cazadores de guanaco de la estepa patagónica. Buenos Aires: Sociedad Argentina de Antropología.

» Mengoni Goñalons, G. (2010). Zooarqueología en la práctica: algunos temas metodológicos. Xama, 19-23, 83-113.

» Michieli, T. C. (1983). Los huarpes protohistóricos. San Juan: Instituto de Investigaciones Arqueológicas y Museo. Facultad de Filosofía, Humanidades y Artes, Universidad Nacional de San Juan.

»Mohn, M. (2010). Las ocupaciones humanas del sitio arqueológico Quebrada Seca 3 en Antofagasta de la Sierra. (Tesis de Licenciatura), Universidad Nacional de Córdoba, Córdoba.

» Montecino Aguirre, S. (2009). Fuegos, Hornos y donaciones. Alimentación y cultura en Rapanui. Santiago de Chile: Editorial Catalonia, FIA-Universidad de Chile.

» Montecino Aguirre, S. y Foerster González, R. (2012). Identidades en tensión: devenir de una etno y gastropolítica en Isla de Pascua. Universum, 27(1), 143-166.

» Orton, C, Tyers, P. y Vince, A. (1993). La cerámica en arqueología. Barcelona: Editorial Crítica, Grijalbo Mondadori. 
» Ots, M. J. (2007). Datos e interpretación sobre la dominación incaica del Valle de Uco, Mendoza. Pacarina (Número Especial), II, 479-485.

» Parisii, M. (1994). Algunos datos de las poblaciones prehispánicas del Norte y Centro Oeste de Mendoza y su relación con la dominación Inca del área. Xama, 4-5, 51-69.

» Pastor, S. y Medina, M. (2013). Prácticas resistentes, elusión y reproducción social en un contexto histórico adverso: Una mirada a los indígenas de Córdoba (Argentina) en tiempos coloniales tempranos. Memoria Americana, 21(1), 65-92.

»Pazzarelli, F. (2008). Notas acerca de una arqueología de la comida. La Zaranda de Ideas. Revista de Jóvenes Investigadores en Arqueología, 4, 157-162.

»Pazzarelli, F. (2010). La importancia de hervir la sopa. Mujeres y técnicas culinarias en los Andes. Antípoda, 10, 157-181.

»Pazzarelli, F. (2011). Arqueología de la comida. Cultura material y prácticas de alimentación en Ambato, Catamarca (Argentina) siglos V-XI. (Tesis Doctoral inédita), Universidad Nacional de Córdoba, Argentina.

"Pollock, S. (Ed.). (2012). Between Feasts and Daily Meals. Towards an Archaeology of Commensal Spaces. Berlin: Edition Topoi.

»Prates, L. y Acosta Hospitaleche, C. (2010). Las aves de sitios arqueológicos del Holoceno tardío de Norpatagonia, Argentina. Los sitios Negro Muerto y Angostura 1 (Río Negro, Argentina). Archaeofauna, 19, 7-18.

» Prieto, C. y Chiavazza, H. (2009a). El ocaso de los pueblos y el inicio de la urbe. Las cerámicas indígenas del valle de Güentata (Mendoza). En F. Oliva, N. de Grandis y J. Rodríguez (Eds.). Arqueología Argentina en los inicios de un nuevo siglo, Vol. II (pp. 1-14). Rosario: Laborde Editor.

» Prieto, C. y Chiavazza, H. (2009b). La Producción Cerámica Viluco entre los siglos XV y XVII (Provincia de Mendoza, Argentina). Chungará. Revista de Antropología Chilena, 41, 261-274.

» Prieto, C., Tobar, V. y Castillo, L. (2006). Estudios de cerámica indígena hallada en el predio Mercedario del Área Fundacional de Mendoza. En H. Chiavazza y V. Zorrilla (Eds.), Arqueología en el predio mercedario de la ciudad de Mendoza (pp.121-156). Mendoza: UNCuyo.

» Prieto, M. R. (2000). Formación y consolidación de una sociedad en un área marginal del Reino de Chile: la Provincia de Cuyo en el siglo XVII. (Tesis Doctoral inédita), Universidad de Sevilla, España.

»Prieto, M. R. y Chiavazza, H. (2006). Aportes de la historia ambiental y la arqueología para el análisis del patrón de asentamiento Huarpe en el oasis norte de Mendoza. Anales de Arqueología y Etnología, 59-60, 159-190.

» Prieto, M. R. y Wuilloud, C. (1986). Consecuencias ambientales derivadas de la instalación de los españoles en Mendoza en 1561. Cuadernos de Historia Regional, II(6), 3-35.

» Prieto, M. R. y Wuilloud, C. (1997). El medio ambiente. En P. Lacoste (Ed.), Diario UNO, Colón y Mendoza colonial (Volumen 2) (pp. 26-40). Mendoza: Editorial Diario Uno.

» Prieto Olavarría, C. (2010a). La cerámica del cementerio de Cápiz Alto (San Carlos, Mendoza). Una aproximación a las identidades culturales. Anales de Arqueología y Etnología, 63-64, 151-175.

» Prieto Olavarría, C. (2010b). Aproximaciones a la producción y función de la cerámica Viluco durante la dominación incaica y los primeros siglos de la colonia en el valle de Mendoza. En J. Bárcena y H. Chiavazza (Eds.), Actas del XVII Congreso Nacional de Arqueología Argentina, (pp. 205-210). Mendoza: Universidad de Cuyo. 
» Prieto Olavarría, C. (2010c). La especialización artesanal alfarera de la cultura Viluco. Norte y centro de la provincia de Mendoza. (Tesis Doctoral inédita), Universidad Nacional de Córdoba, Argentina.

» Prieto Olavarría, C. (2012). La producción y función de la cerámica indígena durante la dominación incaica y la colonia en Mendoza. Intersecciones en Antropología, 13, 71-88.

» Prieto Olavarría, C. y Castro de Machuca, B. (2017). Petrographic characterization and identification of temper sources in local ceramics during the Inca domination and early Spanish colony (Mendoza, west-central Argentina). Journal of Archaeological Science: Reports, 13, 351-360.

»Prieto Olavarría, C. y Chiavazza, H. (2010). La alfarería Viluco y los contextos del Área Fundacional. Aportes al estudio de la dominación incaica y los primeros años de la Colonia en el Valle de Mendoza. En J. R. Bárcena y H. Chiavazza (Eds.), Actas del XVII Congreso Nacional de Arqueología Argentina, (pp. 807-812). Mendoza: Universidad de Cuyo.

» Prieto Olavarría, C. y Chiavazza, H. (2015). Cambios en contextos de colonización: opciones económicas y transformaciones tecnológicas en el norte de Mendoza entre los siglos XV y XVII (Rca. Argentina). Vegueta, 15, 159-184.

» Prieto Olavarría, C., Chiavazza, H., Castillo, L., Tobar, V., Bontorno, E., Porta, V. (2017). Estado actual de las investigaciones de la cerámica indígena del norte de mendoza. tecnología, cronología y distribución. Revista del Museo de Antropología, 1, 95-104.

»Prieto Olavarría, C. y Páez, C. (2015). Presencia de inclusiones piroclásticas en la cerámica de los siglos XV a XVII en el centro oeste y noroeste argentino. Chungara. Revista de Antropología Chilena, 47, 441-453.

» Prieto Olavarría, C. y Tobar, V. (2017). Interacciones y lenguajes visuales en la cerámica local de contextos del período de dominación incaica y coloniales (Centro Oeste Argentino). Estudios Atacameños, 55, 135-161.

»Puebla, L., Zorrilla, V. y Chiavazza, H. (2008). Mendoza en el periodo Colonial Temprano: Mayólicas y Cerámicas locales. En M. T. Carrara (Ed.), Actas del tercer Congreso Nacional de arqueología Histórica (pp. 658-666). Rosario: Universidad de Rosario.

»Quiroga, M., Chiavazza, H., Lascalea, G. y Gurritto, M. (2017). Estudios arqueométricos del registro de clavos procedentes de contextos funerarios de las ruinas de San Francisco (Mendoza). Arqueología, 23(1), 45-6o.

» Rice, P. (1987). Pottery Analisys: a sourcecbook. Chicago: University of Chicago Press

» Rusconi, C. (1942). Acerca del origen del Huarpe. Rotary Club de Mendoza, 98-99, 1-11.

» Rusconi, C. (1962). Poblaciones Pre y post hispánicas de Mendoza (Volumen III). Mendoza: Editorial Imprenta Oficial Mendoza.

» Rye, O. (1981). Pottery Technology. Washington D. C.: Taraxacum.

» Sabadotto, E. y Mansur, A. (2000). Exostósis cartilaginosa múltiple. Actualización. Archivos Argentinos de Pediatría, 98(6), 388.

»Sanders, W. y Price, B. (1968). Mesoamerica. The evolution of a Civilization. Nueva York: Random House.

» Sanhueza, L. (1997). Patrón cerámico: Hacia la definición de un concepto operativo. En Actas del XIV Congreso Nacional de Arqueología Chilena (Tomo II) (pp. 541-570). Copiapó: Universidad de Atacama.

» Sassaman, K. E. (1993). Early pottery in the southeast: Tradition and innovation in cooking technology. Tuscaloosa: University of Alabama Press. 
"Shepard, A. (1976). Ceramic for the archaeologist. Washington D. C.: Carnegie institution of Washington.

» Silveira, M. (1998). Zooarqueología del Templo de San Francisco. En D. Schávelzon (Ed.), Las Ruinas de San Francisco. Arqueología e Historia (pp. 333-335). Mendoza: TINTARMunicipalidad de Mendoza.

"Silveira, M. (2005). Cocina y Comidas en el Río de la Plata. Neuquén: Editorial de la Universidad Nacional del Comahue.

» Sironi, O., Mafferra, L. y López, M. (2016). Una perspectiva arqueológica de los modos del comer en el Predio Mercedario de Mendoza. Anuario de Arqueología, 8, 185 -199.

»Skibo, J. (2013). Understanding pottery function. Nueva York: Springer.

" Skibo, J. (2015). Pottery Use Alteration Analisys. En J. M. Marreiros, J. F. Gibaja Bao y N. Ferreira Bicho (Eds.), Use-wear and Residue Analysis in Archaeology, Manuals in Archaeological Method, Theory and Technique (pp. 189-198). Suiza: Springer.

» Tobar, V. (2013). Los Diseños Decorativos de la Cerámica Viluco (Siglos XV-XVII): Una aproximación a los Lenguajes Visuales Locales. (Tesis de Licenciatura inédita), Universidad Nacional de Cuyo, Argentina.

»Wallerstein, I. (1974). The Modern World Sysytem (Volumen 1). Nueva York: Academic Press.

"Weismantel, M. (1994). Alimentación, género y pobreza en los andes ecuatorianos. Quito: Ediciones Abya-Yala.

»Wolf, E. (2015). Europa y la gente sin historia. México D. F.: FCE. 